\title{
Performance Test of Starch-g-Polyacrylamide Synthesized through Grafting as a Flocculant in Artificial Wastewater Treatment
}

\author{
Mujtahid Kaavessina ${ }^{2, a}$, Ina Fatimah ${ }^{1}$, Suci Soraya ${ }^{1}$ \\ 1 Chemical Engineering, Universitas Sebelas Maret, Surakarta, 57126, Indonesia \\ 2 Bachelor Program of Chemical Engineering, Universitas Sebelas Maret, Surakarta, 57126, Indonesia \\ E-mail: amkaavessina@staff.uns.ac.id (Corresponding author)
}

\begin{abstract}
Flocculation is one of the steps to get clean water. Grafted flocculant was successfully synthesized by combining the benefits of synthetic polymers (polyacrylamide) and natural polymers (cassava starch). This synthesis used "grafting to" method and passed through two stages, i.e. (i) the synthesis of non-terminated polyacrylamide (nt-PAM) and followed by (ii) grafting of non-terminated polyacrylamide (nt-PAM) on the cassava starch. The obtained flocculants were analyzed their molecular structure to determine the success of grafting. Fourier Transform Infra-Red (FTIR) spectra were verifying that polyacrylamide can be attached in the starch molecules. Both neat starch and modified starch were studied as a backbone. The molecular weight of the flocculant is increasing as the increase of acrylamide concentration and polymerization time. The effectiveness of flocculation is relating with the molecular weight. However, the longer chains of attached polyacrylamide show better performance during flocculation than that of shorter chains although the molecular weight was same. The best performance was showed for the flocculant that using: (i) modified starch of cassava as a backbone, (ii) acrylamide concentration of $0.02 \mathrm{M}$ and (iii) polymerization time of 90 minutes. As monitored, it could reduce the turbidity of artificial wastewater about $87,81 \%$
\end{abstract}

Keywords: turbidity, neat starch, modified starch, polyacrylamide, grafted flocculant

EQUILIBRIUM Volume 2 No.1 January 2018

Online at http:// equilibrium.ft.uns.ac.id 


\section{Introduction}

Clean water becomes a basic human necessity and also needed in some industrial processes. Flocculation is one of a series of the treatment stages to obtain clean water. Flocculation can eliminate water turbidity, color, solids in the form of colloidal/suspension particles, and microorganisms. The presence of flocculants in the water will counteract the particle charge that merged into flocs. These flocs will settle gravitationally. There are some kinds of flocculant. Polymeric flocculant has been reported to have more efficient to settle the colloidal particles than the other [1].

Both natural and synthetic polymers have been explored to be made flocculants. Some synthetic polymers reported able to act effectively as a flocculant and didn't require setting the $\mathrm{pH}$ of media. Besides that, it can be used in small doses about 1-5 ppm, formed big floc, and strong binding force to suspended particles [2]. Polyacrylamide is a synthetic polymer that common used as a flocculant. It makes a strong bond with colloidal/suspension particles in treated water. However, it is vulnerable to mechanical friction and difficult to be degraded (undegradable) [3]

In the other hand, the starch (a natural polymer) is a type of polysaccharide that easy to earn, low cost, easy to be degraded (biodegradable), and resistant to mechanical friction. Starch can be obtained from plant sources that it consists of amylose and amylopectin [4]. Thus, it is interested to take benefit properties from both polymers through copolymerization.

Graft copolymerization is the most commonly method used to tailor polymer properties [5]. There are three types of this method, i.e. grafting from, grafting to, and grafting through. In the "grafting from" method, branch chains are grafted onto an active part in the main chain polymers (backbone). While in the "grafting to" method, the active part is on the graft or branch chains. For the "grafting through" method, there are unsaturated part and macromer that have a low molecular weight, so the graft copolymer can be produced as a result of the reaction on unsaturated part by the growing polymer.

In previous study, Kaavessina, et al. (2017) was successfully grafting polyacrylamide to many kinds of starch (taro and cassava starch) in both neat or modified form [6]. The obtained flocculant has also tested in the flocculation of artificial wastewater. The result showed that the performance of this flocculant may be compared to the commercial flocculant. However, it is needed to investigate some factors that influence this performance. This investigation aims to study the influence of acrylamide concentration and polymerization time towards the properties of grafted flocculant and its performance in flocculation.

\section{Experimental Part}

Cassava starch was kindly supplied from local market in Surakarta, Indonesia. The enzyme of $\alpha$-amylase (from Sigma Aldrich) was used to modify the cassava starch enzymatically. Some chemicals, i.e. Acrylamide, $\mathrm{K}_{2} \mathrm{~S}_{2} \mathrm{O}_{8}$, Tetramethylethylendiamin (TMEDA), acetone, methanol and hydroquinone were also purchased from Sigma Aldrich. Nitrogen gas was supplied by PT. Samator Multigas Utama Surakarta. Further, these chemicals were directly used without any treatments.

Redox reaction to synthesize non-terminated/free radical polyacrylamide (nt-PAM) was initiating the copolymerization of starch. This free radical polymer would be attached into the neat/modified cassava starch by substituting the hydroxyl (-OH) groups. The acrylamide concentration was varied about $0.01 \mathrm{M}$ and 0.02 M. While the polymerization time was studied at range between 60-90 minutes. The other conditions of both synthesizing and grafting of nt-PAM were accorded to our previous work [6].

Intrinsic viscosity was measured to determine the molecular weight of starch-g-polyacrylamide by using the correlation between intrinsic viscosity and molecular weight. This correlation was known the Mark Houwink equation [7]:

$$
\eta=\mathrm{KMv}^{\mathrm{a}}
$$

where, $\mathrm{K}=6.31 \times 10^{-3} \mathrm{~g} / \mathrm{ml}$ dan a $=0.8$ for PAm in water

A Perkin-Elmer 630 IR spectrophotometer was determining the molecular structure of starch-gpolyacrylamide within the wave-range at $4000-400 \mathrm{~cm}^{-1}$.

The performance test of grafted flocculants was done by clarifying the artificial wastewater kaolin suspension (10 g of kaolin in $1000 \mathrm{~mL}$ of aquadest). The grafted flocculant $(10 \mathrm{mg}$ ) was dissolved into $20 \mathrm{ml}$ aquadest. Then, a certain dosage of flocculant solution $(4 \mathrm{ml})$ was poured into $500 \mathrm{ml}$ of kaolin suspension. The mixture was agitated for $2 \mathrm{~min}(120 \mathrm{rpm})$ and $10 \mathrm{~min}(50 \mathrm{rpm})$, sequentially. Then, it was allowed for 1 $\mathrm{h}$ and measured the turbidity using EUTECH TN 100 Turbiditymeter. 


\section{Results and Discussion}

The cassava starch was modified enzimatically using $\alpha$-Amylase prior to use as a backbone of grafted flocculant. As described in our previous article [6], the modified starch was visually clearer in water solution and had lower viscosity compared to the neat one. However, the IR spectrum showed this modification was not changing the molecular structure taro starch (see Fig. 1 and Fig 2).

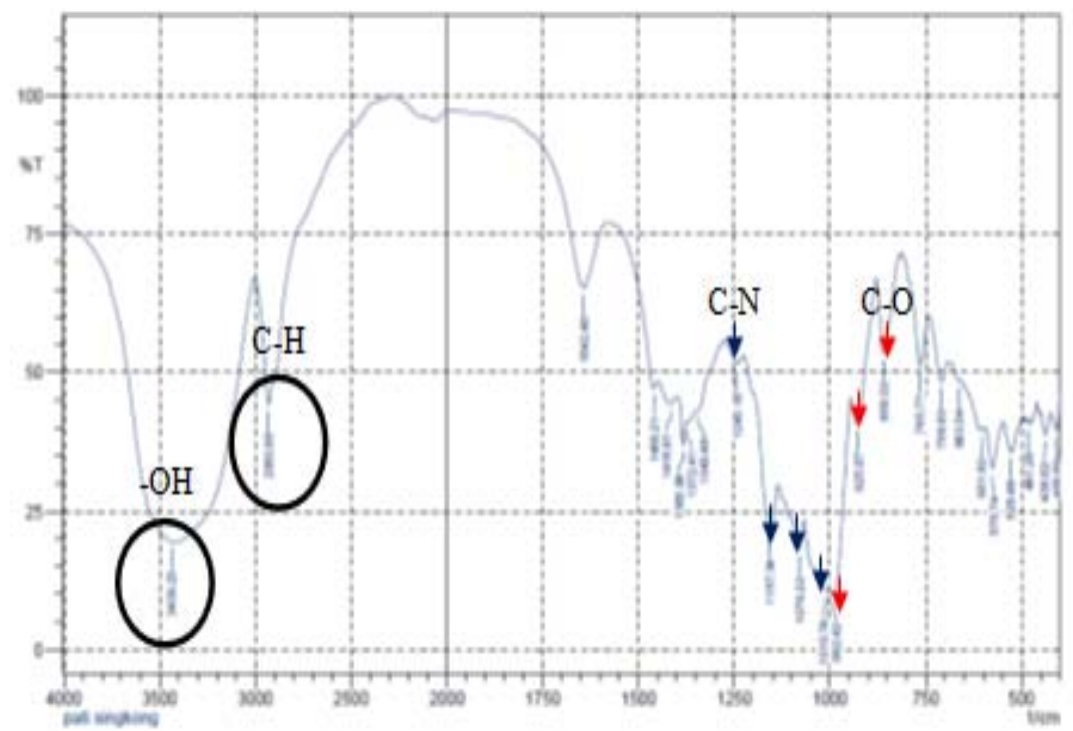

Fig.1. The IR spectrum of neat cassava strach

From Fig.2, it can be monitored that there are three peaks at $859.32 \mathrm{~cm}^{-1}, 925.87 \mathrm{~cm}^{-1}$, and $992.42 \mathrm{~cm}^{-1}$ for the C-O group, at $3439.23 \mathrm{~cm}^{-1}$ peak for the -OH group, at $2930.96 \mathrm{~cm}^{-1}$ peak for the $\mathrm{C}-\mathrm{H}$ group, and the four peaks $1010.74 \mathrm{~cm}^{-1}, 1079.22 \mathrm{~cm}^{-1}, 1157.34 \mathrm{~cm}^{-1}$ and $1243.18 \mathrm{~cm}^{-1}$ for the $\mathrm{C}-\mathrm{N}$ group. These groups are representing for the neat cassava starch.

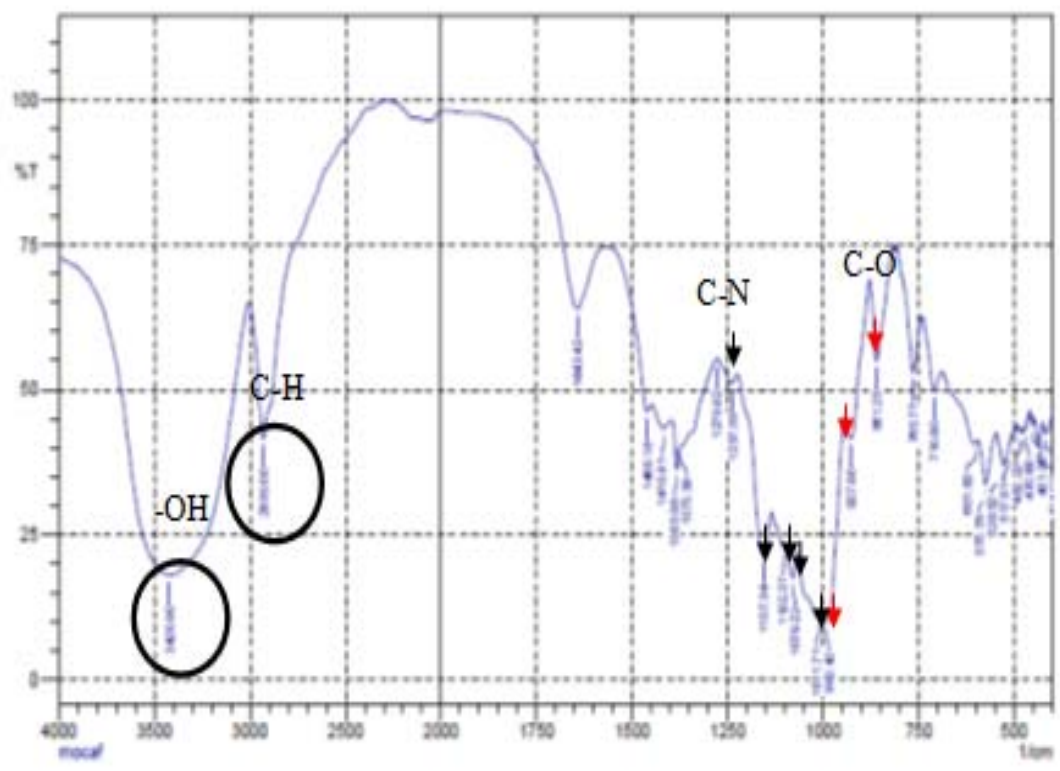

Fig. 2. IR spectrum of modified cassava strach

Compared to the neat cassava starch, all groups are still appearing in the modified one. There is only a peak shift, i.e. for the C-O group is represented by three peaks at $861.25 \mathrm{~cm}^{-1}, 927.80 \mathrm{~cm}^{-1}$ and $992.42 \mathrm{~cm}^{-1}$. The O-H and C-H groups are appeared by peaks at $3420.90 \mathrm{~cm}^{-1}$ and $2930,21 \mathrm{~cm}^{-1}$, respectively. While, for 
C-N group is showed by the five peaks at $1011.71 \mathrm{~cm}^{-1}, 1079.22 \mathrm{~cm}^{-1}, 1102.37 \mathrm{~cm}^{-1}, 1157.34 \mathrm{~cm}^{-1}$ and 1237.39 $\mathrm{cm}^{-1}$.

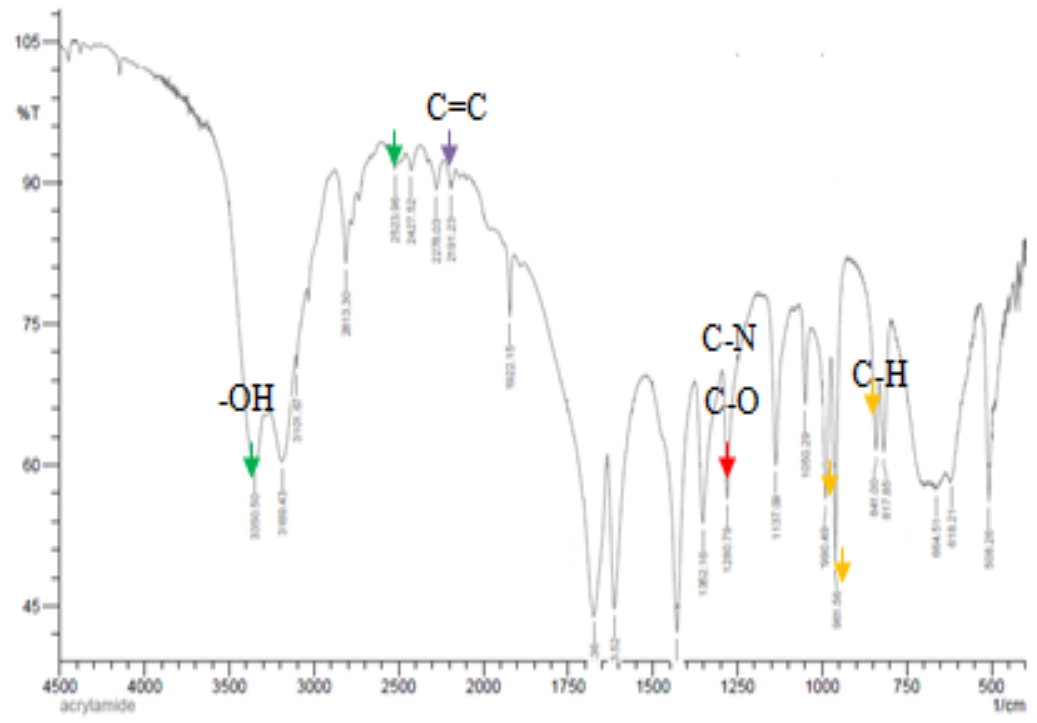

Fig. 3. The IR Spectrum for Acrylamide

The IR spectrum analysis for acrylamide is shown in Fig. 3. The C-O, C=C and C-N groups is appeared at peak $1280.79 \mathrm{~cm}^{-1}, 2191.23 \mathrm{~cm}^{-1}$ and $1280.79 \mathrm{~cm}^{-1}$, respectively. The $\mathrm{C}-\mathrm{H}$ group is shown by three peaks, i.e. $841 \mathrm{~cm}^{-1} ; 961.56 \mathrm{~cm}^{-1}$, and $990.49 \mathrm{~cm}^{-1}$. Two other peaks at $2523.96 \mathrm{~cm}^{-1}$ and $3350.50 \mathrm{~cm}^{-1}$ is represented the O-H group.

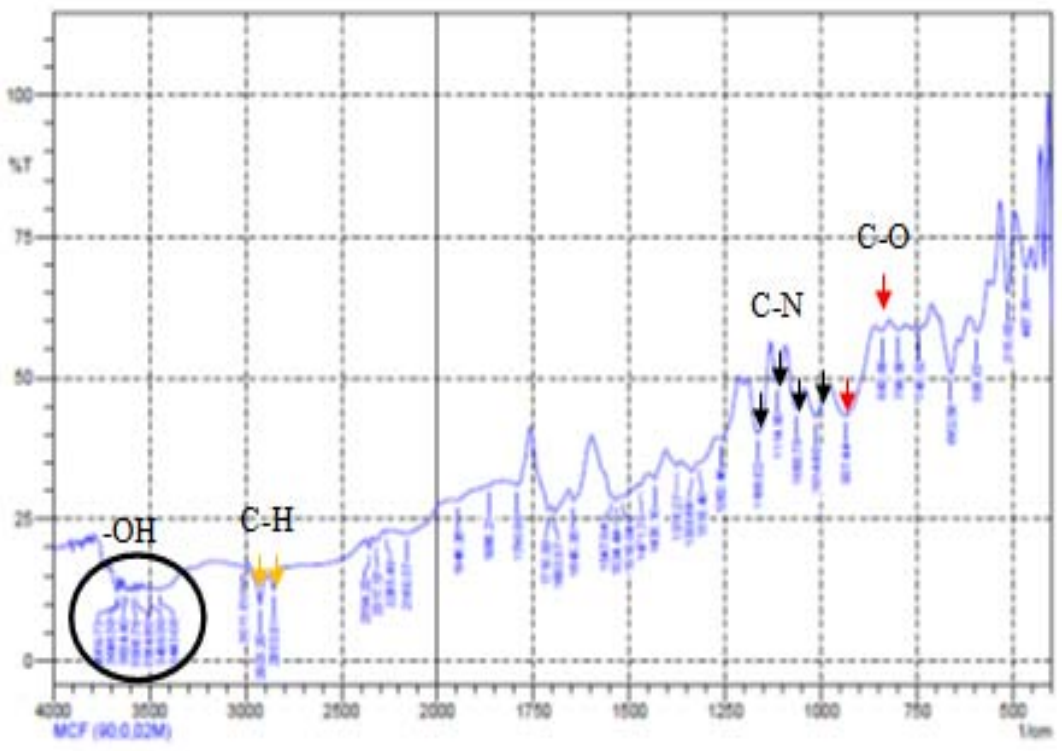

Fig. 4. The IR Spectrum for grafted flocculant with modified cassava starch as a backbone

IR spectrum was also used to analyze the success of acrylamide grafting into the cassava starch. Fig. 4 shows the IR spectrum of grafted flocculant. It can be highlighted that the appearing peaks are combining the peaks between starch and polyacrylamide. It represented that polyacrylamide can be grafted into the starch. The peaks of $\mathrm{O}-\mathrm{H}$ groups in flocculant is not as sharp compared to the starch. It may be explained due to the presence of $\mathrm{O}-\mathrm{H}$ groups was replaced by polyacrylamide chains. 
Table 1. The Peaks of IR Spectra of Neat and Modified Cassava Starch, Acrylamide and Grafted Flocculant

\begin{tabular}{ccccc}
\hline \multirow{2}{*}{$\begin{array}{c}\text { Chemical } \\
\text { bonding }\end{array}$} & $\begin{array}{c}\text { Neat cassava } \\
\text { starch }\end{array}$ & $\begin{array}{c}\text { Wodified } \\
\text { cassava starch }\end{array}$ & Acrylamide & $\begin{array}{c}\text { Grafted } \\
\text { Flocculant }\end{array}$ \\
\hline C-O & 859.32 & 861.25 & 1280.79 & 843.89 \\
& 925.87 & 927.80 & & 937.44 \\
-OH & 992.42 & 992.42 & 2523.96 & 3443.08 \\
& 3439.23 & 3420.90 & 3350.50 & 3499.99 \\
& & & & 3564.60 \\
& & & & 3586.79 \\
& & & & 3624.40 \\
C-H & & & & 3646.58 \\
& 2930.96 & 2930.00 & 961.56 & 3669.73 \\
C-N & & & 990.49 & 2853.81 \\
& 1010.74 & 1011.71 & 1280.79 & 1014.60 \\
& 1079.22 & 1079.22 & & 1063.79 \\
& 1157.34 & 1102.37 & & 1114.90 \\
C=C & 1243.18 & 1157.34 & & 1166.02 \\
& & 1237.39 & & - \\
\hline
\end{tabular}

\subsection{Acrylamide Concentration}

Table 2 shows the effect of acrylamide concentration and modification of starch toward molecular weight of the grafted flocculant. The molecular weight is increasing proportional to the growth of acrylamide concentration. It can be explained that the greater concentration of acrylamide, the longer and more acrylamide chains become active radicals so it is giving the more opportunity of acrylamide to be attached on the starch. This phenomenon was also encountered toward the intrinsic viscosity.

Table 2. The effect of Acrylamide Concentration towards Intrinsic Viscosity $(\eta)$ and Molecular Weight $\left(\mathrm{M}_{\mathrm{W}}\right)$ of Grafted Flocculant

\begin{tabular}{cccc}
\hline Acrylamide Conc. (M) & Grafted Flocculant & $\boldsymbol{\eta}(\mathbf{m l} / \mathbf{g})$ & Mol. Weight $(\mathbf{g} / \mathbf{m o l})$ \\
\hline 0.01 & $\begin{array}{c}\text { Neat Cassava Starch } \\
\text { Modified Cassava }\end{array}$ & 3.31 & $2.5110^{3}$ \\
& $\quad$ Starch & 12.82 & $1.3610^{4}$ \\
0.02 & $\begin{array}{c}\text { Neat Cassava Starch } \\
\text { Modified Cassava } \\
\quad \text { Starch }\end{array}$ & 4.45 & $3.6310^{3}$ \\
& 48.88 & $7.2710^{4}$ \\
\hline
\end{tabular}

Modification of cassava starch shows the increase of molecular weight significantly. It can be explained due the alteration of hydroxyl groups after modification. The $\alpha$-amylase enzyme can revamp hydroxyl groups in starch and make it easier to be substituted with non-terminated polyacrylamide.

The maximum value of intrinsic viscosity and molecular weight obtained in this investigation are 48.88 $\mathrm{ml} / \mathrm{g}$ and $7.2710^{4} \mathrm{~g} / \mathrm{mol}$, respectively. Those values were obtained when the acrylamide concentration is about $0.02 \mathrm{M}$ with modified starch as the backbone. 


\subsection{Polymerization Time}

The preparation of free radical polyacrylamide was done through polymerization of acrylamide monomer without any termination steps. We hypothesized that the length of polyacrylamide is proportional to the polymerization time. The time was studied at range 30-90 minutes. Thus, the length of attached polyacrylamide was studied its performance during the flocculation.

Table 3 shows that the longer of polymerization time of acrylamide caused increasing of intrinsic viscosity and molecular weight of grafted flocculant. The maximum value of intrinsic viscosity and molecular weight were obtained at 90 mins with values of $78.03 \mathrm{ml} / \mathrm{g}$ and $1.30 \times 10^{5} \mathrm{~g} / \mathrm{mol}$, respectively. Those values were obtained when the modified cassava used as the backbone. This phenomenon may be explained as above explanation that the $\alpha$-amylase enzyme can revamp hydroxyl groups in cassava starch.

Table 3. The Effect Polymerization of Acrylamide towards the Intrinsic Viscosity $(\eta)$ and Molecular Weight (MW) of Grafted Flocculant

\begin{tabular}{cccc}
\hline Grafted Flocculant & Polymerization Time $(\mathbf{m i n})$ & $\boldsymbol{\eta}(\mathbf{m l} / \mathbf{g})$ & Mol. Weight $(\mathbf{g} / \mathbf{m o l})$ \\
\hline Neat Cassava Starch & 30 & 4.45 & $3.6310^{3}$ \\
& 60 & 5.85 & $5.1210^{3}$ \\
Modified Cassava Starch & 90 & 8.93 & $8.6910^{3}$ \\
& 30 & 48.88 & $7.2710^{4}$ \\
& 60 & 65.81 & $1.0510^{5}$ \\
\hline
\end{tabular}

\subsection{Flocculation Performance}

Table 4 tabulates the influence grafted flocculant dosage, concentration acrylamide and polymerization time towards turbidity of artificial wastewater (kaolin in water). This table also tabulates the turbidity reduction when neat cassava starch and modified cassava starch were used as a backbone.

Table 4. The percentage of turbidity reduction using studied samples in different dosages

\begin{tabular}{|c|c|c|c|c|c|}
\hline \multirow{2}{*}{$\begin{array}{c}\text { Grafted } \\
\text { Flocculant }\end{array}$} & \multirow{2}{*}{$\begin{array}{l}\text { Acrylamide } \\
\text { Conc. (M) }\end{array}$} & \multirow{2}{*}{$\begin{array}{l}\text { Polymerization } \\
\text { Time (min) }\end{array}$} & \multicolumn{3}{|c|}{ Turbidity Reduction, $\%$} \\
\hline & & & $75^{*}$ & $225^{*}$ & $375^{*}$ \\
\hline \multirow{6}{*}{$\begin{array}{c}\text { Neat } \\
\text { Cassava Starch }\end{array}$} & \multirow[t]{3}{*}{0.01} & 30 & 72.22 & 78.42 & 76.08 \\
\hline & & 60 & 67.30 & 78.57 & 71.44 \\
\hline & & 90 & 75.60 & 82.22 & 78.38 \\
\hline & \multirow[t]{3}{*}{0.02} & 30 & 70.08 & 73.42 & 69.22 \\
\hline & & 60 & 76.66 & 78.57 & 78.41 \\
\hline & & 90 & 75.01 & 81.95 & 74.14 \\
\hline \multirow{6}{*}{$\begin{array}{c}\text { Modified } \\
\text { Cassava Starch }\end{array}$} & \multirow[t]{3}{*}{0.01} & 30 & 75.68 & 73.47 & 66.25 \\
\hline & & 60 & 82.84 & 78.65 & 64.72 \\
\hline & & 90 & 83.81 & 72.01 & 62.47 \\
\hline & \multirow[t]{3}{*}{0.02} & 30 & 76.71 & 75.26 & 70.31 \\
\hline & & 60 & 83.87 & 80.39 & 73.80 \\
\hline & & 90 & 87.81 & 80.35 & 77.54 \\
\hline
\end{tabular}

*Flocculant dosage $(\mu \mathrm{L})$

The maximum reduction of turbidity using neat cassava starch as backbone is about $82,22 \%$ with dosage at $225 \mathrm{ml}$. While for the modified one, the maximum reduction was monitored about $87.81 \%$ with dosage at $75 \mathrm{ml}$. There is phenomenon that the increasing dosage of flocculant is not always increasing percentage of turbidity reduction. It may be concluded that the excess of grafted flocculant is also participating in solution turbidity. 
Comparison between neat and modified starch shows that the modified starch is having better performance in flocculation that that of the neat one. It may be explained that grafted flocculant from modified starch is having more attached polyacrylamide in its chains that that of neat one. As explained above, modification is giving opportunity to revamp hydroxyl group in cassava starch.

\section{Conclusions}

Polyacrylamide was successfully attached to the starch chains by substitution of hydroxyl groups through "grafting to". Modification of cassava starch enzymatically is giving opportunity to attached more polyacrylamide into the starch. The more of attached polyacrylamide will give better performance of grafted flocculant. Also, the longer of polyacrylamide chains is giving an increase of intrinsic viscosity and molecular weight as well as its performance in turbidity reduction. However, the adding grafted flocculant will also participate to the turbidity of solution, thus it is needed the investigation of optimal dosage of use.

\section{References}

[1] Singh, R. P., et al., "Novel Biodegradable Flocculants Based on Polysaccharides", Current Science, 78 (7): 6,2000

[2] Caulfield, M. J., et al., "Some Aspects of the Properties and Degradation of Polyacrylamides", Chemical Reviews, 102(9): 3067-3084, 2002

[3] Rath, S.K., and Singh, R.P., "Flocculation Characteristicof Grafted and Ungrafted Starch, Amylose, and Amylopectin", Journal of Polymer Science, 66, 721-1729, 1997

[4] Belitz, H.D., Grosch, W., and Schieberle, P., Food Chemistry. Verlag Springer, Berlin, 1999

[5] Lee, C. S., et al., "A Review On Application Of Flocculants In Wastewater Treatment" Process Safety and Environmental Protection, 92(6): 489-508, 2014

[6] Kaavessina, M., Distantina, S., and Fadilah, "Synthesis of grafted flocculants based on several kinds of starch and its performance in water turbidity removal", MATEC Web Conf., 101, 01003, 2017

[7] Qudsieh, I. Y., et al., "Preparation and characterization of a new coagulant based on the sago starch biopolymer and its application in water turbidity removal", Journal of Applied Polymer Science, 109 (5): 31403147,2008

[8] Gao, M. and Z. Q. Xu, "Preparation and application of polyacrylamide-grafted starch flocculant". Advanced Materials Research. 875-877: 44-48, 2014 